\title{
EFFECT OF POLYVINYL ALCOHOL OR FETAL CALF SERUM AND WARMING TEMPERATURE ON POST- THAWING SURVIVAL RATE AND IN VITRO MATURATION OF VETRIFIED BUFFALO OOCYTES
}

\author{
Sh. M. Shamiah ${ }^{1}$, K.T. Osman ${ }^{1}$, A.E. Abdel-Khalek ${ }^{2}$ and F.E. El- \\ Keraby $^{1}$ \\ 1- Animal Production Research Institute, Agricultural Research Center, Egypt, 2- \\ Animal Production Department, Faculty Agricultue, Mansoura University, Egypt
}

\section{SUMMARY}

The present study was designed to study the influence of two levels (2 and 4 $\mathrm{mg} / \mathrm{ml}$ ) of Polyvinyl alcohol (PVA), 20\% fetal calf serum (FCS) and no additive in vitrification solution (VS) as well as two thawing temperature degrees (20 and $25^{\circ} \mathrm{C}$ ) on in vitro maturation of buffalo oocytes. Oocytes were recovered from ovarian follicles with diameter of 3-7 $\mathrm{mm}$ by aspiration from ovaries collected from slaughterhouse. Oocytes enclosed in a compact cumulus cells with evenly granulated cytoplasm were selected. Results show that post-thawing survival rate (SR) of all oocytes increased $(P<0.05)$, to 77.4 and $79.6 \%$ with two levels of PVA (2 and 4 $\mathrm{mg} / \mathrm{ml}$ of $\mathrm{VS}$ ), respectively, and to $87.1 \%$ with $20 \% \mathrm{FCS}$ vs. $62.4 \%$ for VS with no additives. The post-thawing survival rate of normal oocytes showed the same trend, being 54.0, 59 and $68.8 \%$ vs.35.4\%, respectively. The effect of post-thawing warming temperature on survival rates was not significant, although these rates tended to be higher with 25 than $20^{\circ} \mathrm{C}$. Maturation rate in term of percentage of oocytes at M IIstage was higher $(P<0.05)$ for fresh than vitrified oocytes (67.6 vs. 21.2-34.0\%). The percentage of oocytes at M II-stage was 34\% for oocytes vitrified with VS and FCS, $26.3 \%$ and $28.7 \%$ with 2 and $4 \mathrm{mg} / \mathrm{ml} P V A$, respectively, and $21.2 \%$ with VS with no additive $(P<0.05)$. In conclusion supplementing VS with PVA (2 or $4 \mathrm{mg}$ ) or FCS (20\%) improves maturation rate of vitrified buffalo oocytes.

Keyword: buffalo, in vitro, oocyte maturation, vetrification

\section{INTRODUCTION}

In a comparative study of Shamiah (1997), recovery rate of acceptable oocytes was lower in buffalo compared to bovine (5.8 vs.11.9\%). Freezing oocytes was adopted for genetic resources conservation and to safe breeds in dangerous. Several investigators have attempted to freeze mammalian oocytes (Hernandez-Ledezma et al., 1989 \& Parks and Ruffing, 1987) but limited ones gave attention to buffaloes (Wani et al., 2004 and Yadav et al., 2008). Different protocols considering types and concentrations of cryoprotectants, numbers of equilibration steps, types of cryopreservation device, times of exposure and numbers of dilution steps at warming

Issued by The Egyptian Society of Animal Production 
(Vajta et al., 1998; Massip et al., 1987 and Dattena et al., 2000) were executed through the last 15 years.

Number of studies were conducted to replace biological proteins in vitrification solution (VS) for rodent oocytes (Fuku et al., 1995 and Nowshari and Brem 2000). However, VS for in vitro matured bovine oocytes are usually supplemented with fetal calf serum (FCS) and bovine serum albumin (BSA) as a macromolecular source of protein (Grill et al., 1980). The macromolecules polyvinyl alcohol (PVA) and polyvinyl pyrrollidone (PVP) have also been used to substitute serum in the culture medium of bovine oocytes (Pugh et al., 2000) with advantage of PVA due to its lower toxicity (Fuku et al., 1995).

Critical warming rates needed to avoid ice crystal formation during warming were found to have many orders of magnitude higher than critical cooling rates needed to avoid ice crystal formation during cooling (Baudot and Odagescu, 2004).

In the light of lacking information concerning buffaloes oocyte cryopreservation, the current study was planned to investigate the effect of two factors, levels of PVA and warming temperature degrees during thawing on rehydration on in vitro maturation of buffalo oocytes.

\section{MATERIALS AND METHODS}

This study was carried out at the International Livestock Management Training Center, Sakha, belonging to the Animal Production Research Institute, Agricultural Research Center, Ministry of Agriculture during the period from July 2006 to April 2008. All chemicals used in this study were purchased from Sigma (Madrid, Spain), unless otherwise indicated.

\section{Oocyte recovery:}

Ovaries collected from slaughtered buffaloes were placed in $\mathrm{NaCl}$ solution ( 9 $\mathrm{mg} / \mathrm{ml}$ ) containing antibiotics (penicillin, $100 \mathrm{UI} / \mathrm{ml}$ and streptomycin sulphate, 100 $\mu \mathrm{g} / \mathrm{ml}$ ) and maintained at $25-30{ }^{\circ} \mathrm{C}$ until oocyte recovery. The collected ovaries were washed twice in distilled water and once in freshly prepared saline. Ovarian follicles of 3-7 $\mathrm{mm}$ in diameter were aspirated using 18-gauge needle connected to a syringe. Follicular fluids were placed in Petri dishes for oocyte collection, and then oocytes were examined under stereomicroscope. Oocytes enclosed in a compact cumulus with evenly granulated cytoplasm were selected and washed three times in Dulbecco's phosphate buffer solution (DPBS) medium.

\section{Vitrification and warming:}

The basal solution used for vitrification was DPBS (Gibco) supplemented with polyvinyl alcohol (PVA) (average molecular weight 30,000-70,000; Sigma) at levels of 2 and $4 \mathrm{mg} / \mathrm{ml}$ to be compared with FCS (20\% v: v, Sigma) and non-supplemented DPBS.

The vitrification procedures employed throughout this experiment were according to Asada et al. (2002) with some modification. Vitrification solution (VS) containing $40 \%$ (V: V) ethylene glycol (EG) and $0.5 \mathrm{M}$ sucrose in basal medium was used. Ten compact oocytes cumulus cells (COCs) were loading into the center between two air bubbles in $0.25 \mathrm{ml}$ plastic insemination straws (IVM L' Aigle, France) using a fine 
glass capillary pipette. After heat-sealing the straws were plunged immediately into liquid nitrogen (LN2) within $30 \mathrm{sec}$ at room temperature.

After storage for two weeks, the oocytes were warmed by holding the straws for 6 sec in air and then agitating them in water bath at 20 or $25^{\circ} \mathrm{C}$ for at least $15 \mathrm{sec}$. (The contents of each straw were emptied into Petri dish and oocytes were transferred to three diluents solution, $0.5 \mathrm{M}$ and $0.25 \mathrm{M}$ sucrose in DPBS supplemented with $10 \%$ BSA), then in DPBS supplemented with $10 \%$ BSA for 3 min per solution, to remove of intracellular cryoprotectant (Asada et al., 2002).

\section{Evaluation of oocyte viability:}

Oocyte viability was evaluated morphologically based on the integrity of the oolemma and zona pellucida; loss of membrane integrity was obvious upon visual inspection as the sharp demarcation of the membrane disappeared and the appearance of the cytoplasm changed.

The criteria used for assessing the post-thaw morphology of vitrified-warmed oocytes were as follows: normal oocytes, with spherical and symmetrical shape with no sings of lysis and damage oocytes, crack in zona pellucida, oocytes split in two halves, change in shape of oocytes and leakage of oocytes contents (Figs. 1-5, Dhali et al., 2000).

\section{Oocyte maturation:}

Complex tissue culture medium (TCM-199, powder) was dissolved in deionized double distilled water and $50 \mu \mathrm{g} / \mathrm{ml}$ gentamicin was added to the medium. On the day of maturation, TCM-199 medium stock was supplemented with $10 \%$ FCS, $0.5 \mu \mathrm{g} / \mathrm{ml}$ FSH, $10 \mu \mathrm{g} / \mathrm{ml} \mathrm{LH}$ (Pregnyl, Nile, CO. for Pharm. Cairo, Egypt), $1 \mu \mathrm{g} / \mathrm{ml}$ estradiol $\beta_{17}, 20 \mathrm{mmol}$ final concentration of pyruvate, $50 \mu \mathrm{g} / \mathrm{ml}$ gentamicin. The $\mathrm{pH}$ value of the medium was adjusted at 7.3-7.4 and osmolarity at $280-300 \mathrm{mOsmol} / \mathrm{kg}$. The medium was filtrated by $0.22-\mu \mathrm{m}$ millipore filter (Shamiah, 2004).

Each of $500 \mu \mathrm{l}$ from prepared maturation medium was placed into a four well dishes and covered by sterile mineral oil. Before placing oocytes into culture dishes, the medium was incubated in $\mathrm{CO}_{2}$ incubator $\left(5 \% \mathrm{CO}_{2}\right.$, at $39^{\circ} \mathrm{C}$ and high humidity) for 60 minutes.

After warming, oocytes were washed three times in each of PBS plus 3\% BSA and once in TCM-199. Thereafter, fresh or vitrified oocytes were placed in the medium and incubated for $24 \mathrm{~h}$ at $39^{\circ} \mathrm{C}, 5 \% \mathrm{CO} 2$ and high humidity.

\section{Fixation, staining and examination of oocytes:}

After $24 \mathrm{~h}$ as a maturation period, oocytes were washed using PBS containing 1 $\mathrm{mg} / \mathrm{ml}$ hyaluranidase to remove the cumulus cells. Then, oocytes were washed two times in PBS supplemented with 3\% BSA and loaded on clean slide. Slides were placed into fixation solution (3 ethanol: 1 glacial acetic acid) overnight. Thereafter, oocytes were stained with $1 \%$ orcein in $45 \%$ acetic acid and examined for maturation under phase-contrast microscopy as the following: Matured oocytes: Chromosome at metaphase II (MII) and polar body exhausted in previtilline space, oocytes with germinal vesicle (GV): Chromosomal in disk in cytoplasmic with intact membrane of nuclei, oocytes with germinal vesicle breakdown (GVBD): Chromosomal in disk in cytoplasmic but intact membrane of nuclei is breakdown, 
oocytes at metaphase $1 \mathrm{M} 1$ and metaphase MII and degenerated oocytes: Oocytes were vaculated or cytoplasmic shrinked or chromatin condensed (Shamiah, 2004).

\section{Statistical analysis:}

The experiment was replicated 5 times for both survival rates (Factorial design) and maturation rates (one way). The data were statistically analyzed by analysis of variance (ANOVA) after arcsine transformation. Dunacn's Multiple Range Test was followed for test the significant differences among treatments or storage times (Duncan, 1955).

\section{RESULTS AND DISCUSSION}

\section{Effect of type of additives to vetrification solution (VS):}

Adding either PVA or FCS to vertification solution (DPBS) increased $(\mathrm{P}<0.05)$ post-thawing survival rate of buffalo oocytes by about $15-25 \%$ in term of total oocytes and by about $20-34 \%$ in term of normal oocytes. However, post-thawing survival rate of abnormal oocytes insignificantly decreased from 27.1 to $18.3-23.4 \%$ by adding both levels of PVA or FCS. Adding FCS improved oocyte survival rates compared to two PVA levels, however, the differences were non-significant (Table $1)$.

Table 1. Post-thawing survival rate (\%) of immature buffalo oocytes vitrified in DPBS medium as affected by type of additives to vetrification solution

\begin{tabular}{|c|c|c|c|c|c|c|c|}
\hline \multirow{3}{*}{$\begin{array}{l}\text { Type of } \\
\text { Additive }\end{array}$} & \multirow{3}{*}{$\mathbf{N}$} & \multicolumn{6}{|c|}{ Post-thawing survival } \\
\hline & & \multicolumn{2}{|c|}{ Total oocytes } & \multicolumn{2}{|c|}{ Normal oocytes } & \multicolumn{2}{|c|}{ Abnormal oocytes } \\
\hline & & $\mathbf{n}$ & $\%$ & $\mathbf{n}$ & $\%$ & $\mathbf{n}$ & $\%$ \\
\hline No additive & 229 & 143 & $62.4^{\mathrm{b}}$ & 81 & $35.4^{\mathrm{b}}$ & 62 & 27.1 \\
\hline PVA $(2 \mathrm{mg} / \mathrm{ml})$ & 252 & 195 & $77.4^{\mathrm{a}}$ & 136 & $54.0^{\mathrm{a}}$ & 59 & 23.4 \\
\hline PVA (4 mg/ml) & 221 & 176 & $79.6^{\mathrm{a}}$ & 131 & $59.3^{\mathrm{a}}$ & 45 & 20.4 \\
\hline FCS $(20 \%)$ & 224 & 190 & $87.1^{\mathrm{a}}$ & 147 & $68.8^{\mathrm{a}}$ & 43 & 18.3 \\
\hline
\end{tabular}

$\mathrm{a}$ and $\mathrm{b}$ : Percentages in the same column with different superscripts are significantly different at $\mathrm{P}<0.05$.

$\mathrm{N}$ : Total number of vitrified oocytes.

Obtained post-thawing survival rates for recovered oocytes are lower than that recorded in buffaloes by Dhali et al. (2000) (92.3\%) and in bovine by Asada et al. (2002) and Hamano et al. (1993) (49.5 to 87.5\%). Improvement in survival rate in buffalo oocytes by adding PVA or FCS to vetrification medium comes in agreement with the results of Naitana et al. (1997) in sheep and Sommerfeld and Niemann (1999) in bovine. This may be due to decrease toxicity of cryoprotectans and change the physical properties of the solution (Shaw et al., 2000 and Woods et al., 2004). Moreover, it may protect cell membranes during freezing process (Naitana et al., 1997).

\section{Effect of warming temperature (thawing):}

Post-thawing warming temperature did not affect significantly survival rates of total, normal and abnormal recovered buffalo oocytes, although survival rates of total and normal oocytes tended to be higher with 25 than $20^{\circ} \mathrm{C}$ (Table 2). 


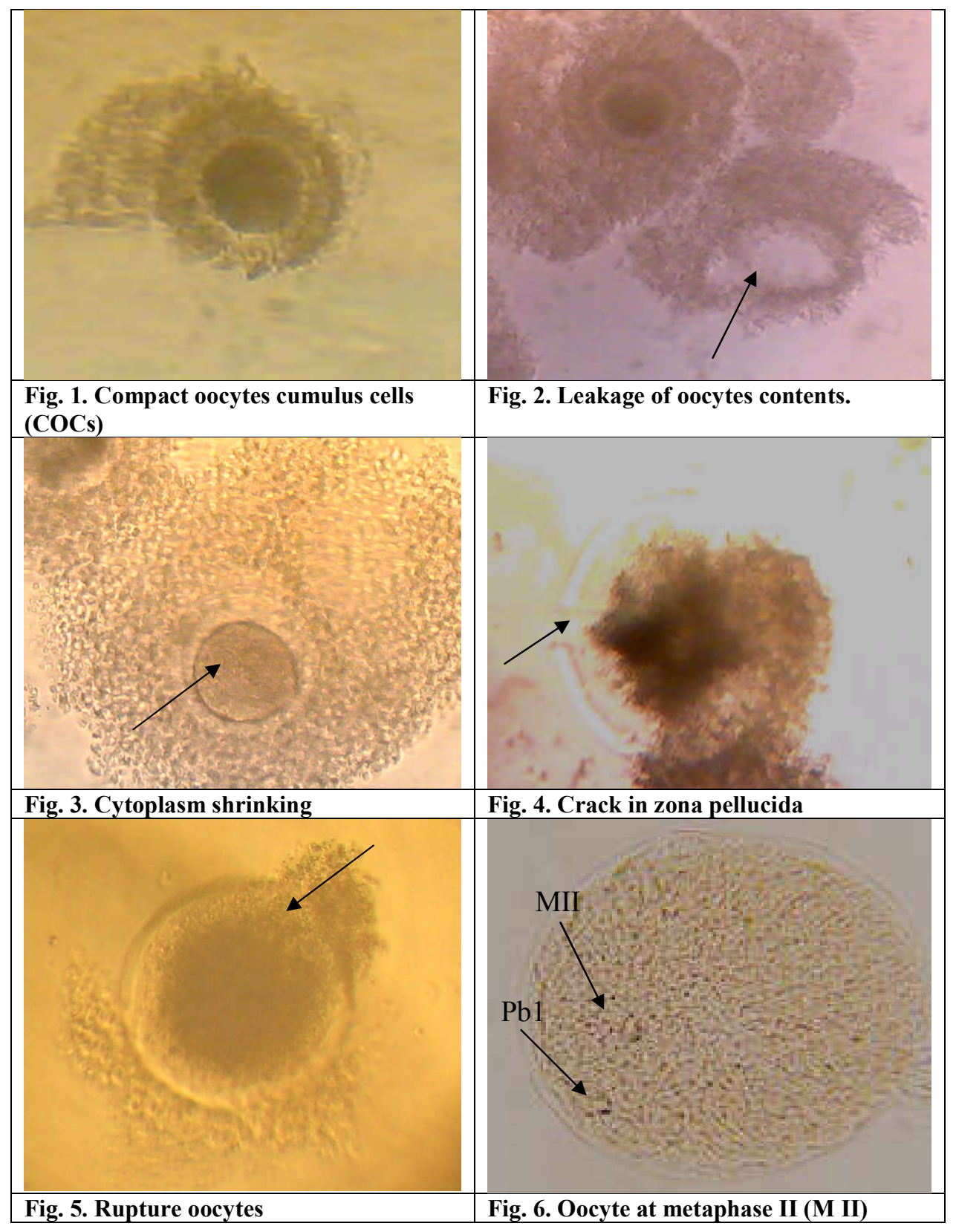


Table 2. Post-thawing survival rate (\%) of immature buffalo oocytes vitrified in DPBS medium as affected by warming temperature

\begin{tabular}{|c|c|c|c|c|c|c|c|}
\hline \multirow{3}{*}{$\begin{array}{c}\text { Warming } \\
\text { temperature } \\
\left({ }^{\circ} \mathrm{C}\right)\end{array}$} & \multirow{3}{*}{$\mathbf{N}$} & \multicolumn{6}{|c|}{ Post-thawing survival } \\
\hline & & \multicolumn{2}{|c|}{ Total oocytes } & \multicolumn{2}{|c|}{ Normal oocytes } & \multicolumn{2}{|c|}{ Abnormal oocytes } \\
\hline & & $\mathbf{n}$ & $\%$ & $\mathbf{n}$ & $\%$ & $\mathbf{n}$ & $\%$ \\
\hline 20 & 477 & 357 & 74.8 & 248 & 52 & 109 & 22.9 \\
\hline 25 & 449 & 347 & 77.3 & 247 & 55 & 100 & 22.3 \\
\hline
\end{tabular}

$\mathrm{N}$ : Total number of vitrified oocytes.

Whittingham et al. (1972) reported that rapid warming of mammalian cells after cryopreservation was always better because cells had shorter times to recrystalize and were exposed for less time to cryoprotectants. Generally, warming temperature was reported to interacte with cooling temperature on post-thawing survival rates of oocytes (Orief et al., 2005).

\section{In vitro maturation:}

Present results cleared that the maturation rate in term of percentage of oocytes reached M II-stage was higher $(\mathrm{P}<0.05)$ for fresh than vitrified oocytes (Table 3 and Fig. 6). Among vitrified oocytes, the percentage of matured oocytes was higher (34\%) for those vitrified in FCS, followed by 2 and $4 \mathrm{mg} / \mathrm{ml} \mathrm{PVA} \mathrm{compared} \mathrm{to} \mathrm{those}$ with no additive.

It is of interest to note that the lower percentage of oocytes at M II-stage for vitrified than fresh oocytes was attributed to degeneration of oocytes during vitrification.

Table 3. In vitro maturation of buffalo oocytes vitrified in vetrification solution with different additives as compared to fresh oocytes

\begin{tabular}{|c|c|c|c|c|c|c|c|c|c|c|c|}
\hline \multirow{3}{*}{ Type of oocyte } & \multirow{3}{*}{$\mathbf{N}$} & \multicolumn{8}{|c|}{ Maturation stage } & \multirow{2}{*}{\multicolumn{2}{|c|}{$\begin{array}{c}\text { Degenerated } \\
\text { oocytes }\end{array}$}} \\
\hline & & \multicolumn{2}{|c|}{ G.V } & \multicolumn{2}{|c|}{ G.V.B } & \multicolumn{2}{|c|}{ M I } & \multicolumn{2}{|c|}{ M II } & & \\
\hline & & $\mathbf{N}$ & $\%$ & $\mathbf{n}$ & $\%$ & $\mathbf{n}$ & $\%$ & $\mathbf{n}$ & $\%$ & $\mathbf{N}$ & $\%$ \\
\hline Vitrified with no additive & 85 & 9 & 10.6 & 14 & 16.5 & 4 & 4.7 & 18 & $21.2^{\mathrm{d}}$ & 40 & $47.0^{\mathrm{a}}$ \\
\hline Vitrified with PVA $(2 \mathrm{mg} / \mathrm{ml})$ & 95 & 14 & 14.7 & 13 & 13.7 & 5 & 5.3 & 25 & $26.3^{c}$ & 38 & $40.0^{\mathrm{a}}$ \\
\hline Vitrified with PVA (4 mg/ml) & 101 & 11 & 10.9 & 8 & 7.9 & 7 & 6.9 & 29 & $28.7^{\mathrm{c}}$ & 46 & $45.6^{\mathrm{a}}$ \\
\hline Vitrified with FCS (20\%) & 100 & 8 & 8.0 & 7 & 7.0 & 9 & 9.0 & 34 & $34.0^{\mathrm{b}}$ & 42 & $42.0^{\mathrm{a}}$ \\
\hline Fresh oocytes & 105 & 4 & 3.8 & 5 & 4.8 & 10 & 9.5 & 71 & $67.6^{\mathrm{a}}$ & 15 & $14.3^{\mathrm{b}}$ \\
\hline
\end{tabular}

In this respect, many authors found that the developmental ability of oocytes frozen at germinal vesicle (GV) stage was lower than that in vivo or in vitro matured oocytes recovered from buffaloes ( Parkway et al., 2007 and Abdoon et al., 2002) and cattle (Lim et al., 1992). The ultrastructural damages to the oocytes deleterious effects on chromosome and other cytoplasmic structure during cryopreservation of 
mouse (Van der Elst et al., 1992) and human oocytes (Park et al., 1997) may provide an rational explanation for the lower development rates of verified oocytes. Moreover, exposure to cryoprotectant or lower temperature may cause a damage in microtublar spindle formation of M II as observed in mouse and human oocytes (Pickering et al., 1990 and Van der Elst et al., 1988).

In conclusion supplementing VS with PVA ( 2 or $4 \mathrm{mg}$ ) or FCS (20\%) improves maturation rate of vitrified buffalo oocytes.

\section{REFERANCES}

Abdoon, A.S.S., Omaima, M. Kandil, T. Otoi and T. Suzuki, 2001. Influence of oocyte quality, culture media and gonadotropins on cleavage rate and development of in vitro fertilized buffalo embryos Animal Reproduction Science 65:215-223.

Asada, M., S. Ishibashi, Ikumi, and Y. Fukui, 2002. Effect of poly vinyl alcohol (PVA) concentration during vitrification on in vitro matured bovine oocytes. Theriogenology, 58: 1199-1208.

Barkawi, A.H., S.A. Ibrahim, G. Ashour, Amal K. El-Asheeri, Y.M. Hafez, and Marwa, S. Faheem, 2007. In vitro production of buffalo (Bubalus bubalis) embryos. Egyptian J. Anim. Prod. 44 (1):335-48.

Baudot, A. and V. Odagescu, 2004. Thermal properties of ethylene glycol aqueous solutions. Cryobiology 48, 283-294.

Dattena, M., G. Ptak, P. Loi and P. Cappai, 2000. Vitrification of in vivo derived (IVD) ovine embryos in two different devices: open pulled-straws and French mini-straws. Proc ICAR, Sandnes-Norway: 66 (abstract).

Dhali, A., R.S. Manik, S.K. Das, S.K. Singla and P. Plata, 2000. Vitrification of buffalo (Bubalus bubalis) oocytes. Theriogenology, 53: 1295-1303.

Duncan, D.B., 1955. Multiple range and multiple F. Test biometrics.; 11: 1-42.

Fuku, E., J. Liu and B.R. Downey, 1995. In vitro viability and ultrastructural change in bovine oocytes treated with a vitrification solution. Mol. Reprod. Dev., 40: 177-185.

Grill, G., A. Porcellini and G. Lucarelli, 1980. Role of serum on cryopreservation and subsequent viability of mouse bone narrow haemopoetic stem cells. Cryobiology, 17: 516-520.

Hamano, S., A. Koikeda, M. Kuwayana and T. Nagai, 1993. Full term development of in vitro matured and vitrified and fertilized bovine oocytes. Theriogenology, 45:1085-1090.

Hernandez-Ledezma, J.J., R.W. Wright, Jr. 1989. Deep freezing of mouse one-cell embryos and oocytes using different cryoprotectants. Theriogenology, 32: 735743.

Lim, J.M., Y. Fukui, and H. Ono, 1992. Development competence of bovine oocytes frozen at various maturation stages followed by in vitro maturation and fertilization. Theriogenology, 37: 351-361.

Massip, A., P. Van Der Zwalmen and F. Ectors, 1987. Recent progress in cryopreservation of cattle embryos. Theriogenology, 27: 69-79.

Miyake, T., M. Kasai, S.F. Zhu, T. Sakurai and T. Machida, 1993. Vitrification of mouse oocytes and embryos at various stage of development in an ethylene glycol-based solution by simple method. Theriogenology, 40: 121-134. 
Naitana, S., S. Ledda, P. Loi, G. Leoni, L. Bogliolo and M. Dattena, 1997. Polyvinyl alcohol as a defined substitute for serum in vitrification and warming solutions to cryopreserved ovine embryos at different stage of development. Anim. Reprod. Sci., 48: 247-256.

Nowshari, M.A. and G. Brem, 2000. The protective action of poly vinyl alcohol during rapid freezing of mouse embryos. Theriogenology, 53: 1157-1166.

Orief. Y., K. Dafopoulos, A Schultze-Mosgau and S. El-Hasani, 2005. Vitrification: will it replace the conventional gamete cryopreservation Techniques?. Middle East Fertility Society Journal, 3: 171-184.

Palasz, A.T. and R.J. Mapletoft, 1996. Cryopreservation of mammalian embryos and oocytes: Recent Advances. Biotechnol. Adv., 14:127-149.

Park, S.E., W.Y. Son, S.H. Lee, K.A. Lee, J.J. Ko and K.Y. Cha, 1997. Chromosome and spindle configurations of human oocytes matured in vitro after cryopreservation at the germinal vesicle stage. Fertility and Sterility, 68: 920-926.

Parks, J.E. and N.A. Ruffing, 1987. Factors affecting low temperature survival of frozen human oocytes. Gamete Res. 16: 343-354.

Pickering, S.J., P.R. Braude, M.H. Johnson, A. Cant and J. Currie, 1990. Transient cooling to room temperature can cause irreversible disruption of the meiotic spindle in the human oocyte. Fertil. Steril., 54:102-108.

Pugh, P.A., H.R. Tervit and H. Niemann, 2000. Effect of vitrification medium composition on the survival of bovine in vitro produced embryos, following in straw-dilution, in vitro and in vivo following transfer. Anim. Reprod. Sci., 58: 922.

Shamiah, S.M., 1997. Some factors affecting in vitro maturation and fertilizing capacity of oocytes in some farm animals. M. Sc. Thesis, Faculty of Agriculture, Minufiya University, Egypt.

Shamiah, Sh. M. (2004). Studies on in vitro fertilization in Egyptian buffaloes. Ph.D. Thesis, Faculty of Agriculture, Mansoura University, Egypt.

SAS, 1996. SAS/Stat. User's Guide Static's, Ver., 6.06 4th Ed. SAS Institute Inc. Cary, NC.

Shaw, J.M., A. Oranratnachai and A.O. Trounson, 2000. Fundamental cryobiology of mammalian oocytes and ovarian tissue. Theriogenology, 53:59-72.

Sommerfeld, V. and H. Niemann, 1999. Cryopreservation of bovine in vitro produced embryos using ethylene glycol in controlling freezing and vitrification. Cryobiology, 38: 95-105.

Vajta, G., P. Holm, M. Kuwayama, P.J. Booth, H. Jacobsen and T. Greve, 1998. Open pulled straw (OPS) vitrification: a new way to reduce cryoinjuries of bovine ova and embryos. Mol. Reprod. Dev., 51: 53-8.

Van der Elst, J., E. Van den Abbeel, R. Jacobs, E. Wisse and A. Van Steirteghem, 1988. Effect of 1,2-propandiol and dimethylsulfoxide on the meiotic spindle of the mouse oocyte. Hum. Reprod. 3: 960-967.

Van der Elst, J., S. Nerinckx and A.C. Van Steirteghem, 1992. In vitro maturation of mouse germinal vesicle-stage oocytes following cooling, exposure to cryoprotectants and ultrarapid freezing: Limited effect on the morphology of the second meiotic spindle. Hum. Reprod., 7: 1440-1446.

Vieira, A.D., A. Mezzalira, D.P. Barbieri, R.C. Lehmkuhl, M.I.B. Rubin and G. Vajta. 2002. Calves born after open pulled straw vitrification of immature bovine oocytes. Cryobiology, 45: 91-4. 
Wani, N.A., S.N. Maurya, A.K. Misra, V.B. Savena and B.D. Lakhchaura, 2004. Effect of cryoprotectants and their concentration on in vitro development of vitrified- warmed immature oocytes in buffalo (Bubalus bubalis). Theriogenology, 61: 831-842.

Whittingham, D.G., S.P. Leibo and P. Mazur, 1972. Survival of mouse embryos frozen to $196^{\circ} \mathrm{C}$ and $-269^{\circ} \mathrm{C}$. Science $178: 411-414$.

Woods, E.J., J.D. Benson, Y. Agca and J.K. Critser, 2004. Fundamental cryobiology of reproductive cells and tissues. Cryobiology, 48:146-56.

Yadav, R. C.; A. Sharma, N. Garg and Purohit, G. N. (2008). Survival of vitrified water buffalo cumulus oocytes complex and their subsequent development in vitro. Bulgarian Journal of Veterinary Medicine, 11, No 1, 55-64. 


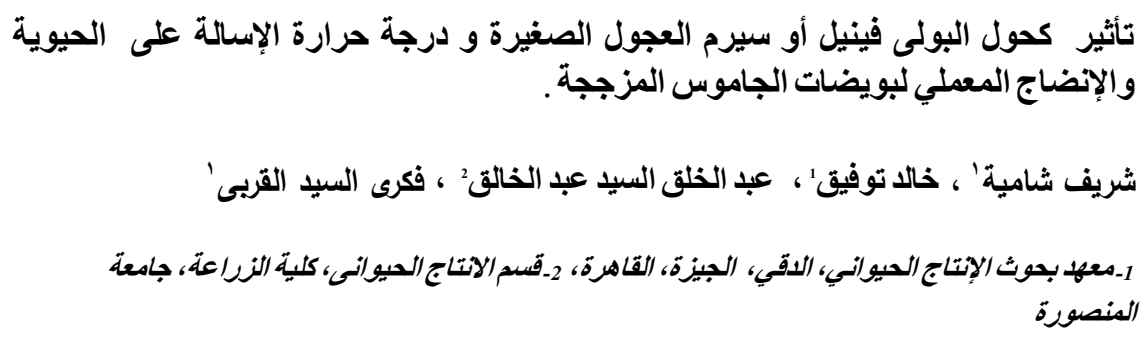

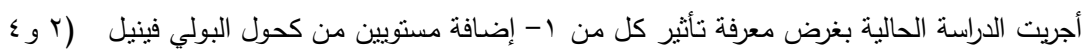

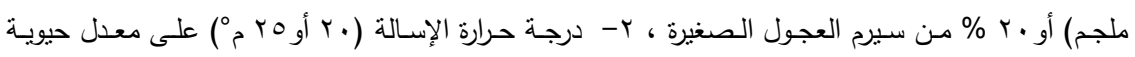

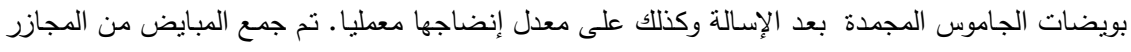

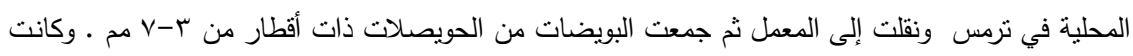

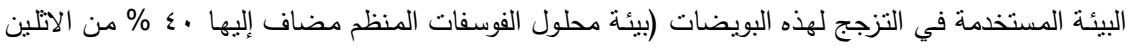

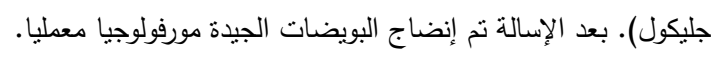

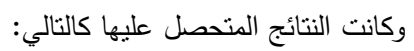

1 (p<0.05), في معدل الاسترداد للبويضات الإنسات

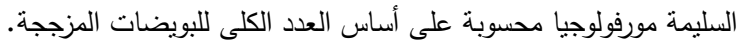

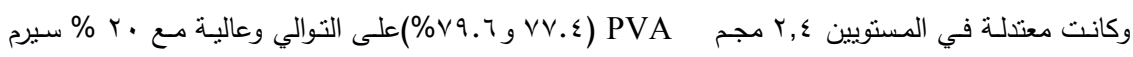

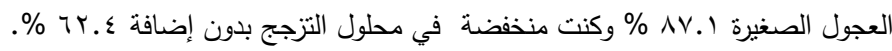

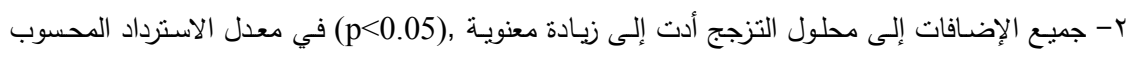

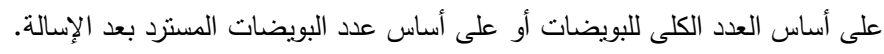

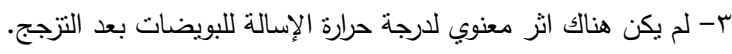

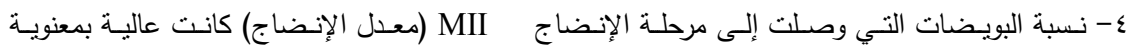

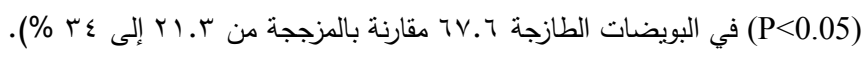

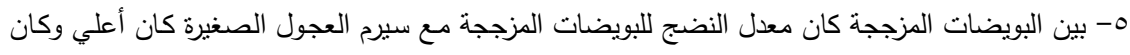

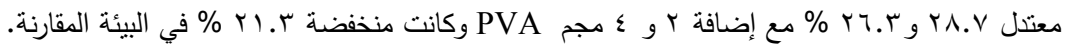
الخلاصة أنة يمكن استخدام PVA أو سيرم العجول الرضيعة لتحسين معدل إنضاج البويضات 